\title{
Firefly Algorithm Based on Euclidean Metric and Dimensional Mutation
}

Jing Wang, Jiangxi University of Finance and Economics, China

Yanfeng Ji, Jiangxi University of Finance and Economics, China

\begin{abstract}
Firefly algorithm is a meta-heuristic stochastic search algorithm with strong robustness and easy implementation. However, it also has some shortcomings, such as the "oscillation" phenomenon caused by too many attractions, which makes the convergence speed too slow or premature. In the original FA, the full attraction model makes the algorithm consume a lot of evaluation times, and the time complexity is high. Therefore, in this paper, a novel firefly algorithm (EMDmFA) based on Euclidean metric (EM) and dimensional mutation (DM) is proposed. The EM strategy makes the firefly learn from its nearest neighbors. When the firefly is better than its neighbors, it learns from the best individuals in the population. It improves the FA attraction model and dramatically reduces the computational time complexity. At the same time, DM strategy improves the ability of the algorithm to jump out of the local optimum. The experimental results show that the proposed EMDmFA significantly improves the accuracy of the solution and better than most state-of-the-art FA variants.
\end{abstract}

\section{KEYWORDS}

Dimensional Mutation, Euclidean Metric, Firefly Algorithm, Global Optimization, Meta-Heuristic Algorithm

\section{INTRODUCTION}

Many problems in the real world can be transformed into optimization problems, but with the development of the times, these problems become more and more complex. One of the greatest challenges is high-dimensional nonlinear problems. Therefore, some new meta-heuristic swarm intelligence algorithms have been proposed, such as artificial bee colony algorithm (ABC) (Karaboga \& Basturk, 2007), particle swarm optimization algorithm (PSO) (Kennedy \& Eberhart, 1995) and cuckoo search (CS) (Yang \& Deb, 2009). As a member of the swarm intelligence algorithm, the Firefly algorithm (FA) (Yang, 2010) has attracted many scholars' attention due to its simple structure, few parameters and easy implementation. Until now, FA has been successfully applied in various fields such as image recognition and path planning (Wang, Guo, Duan, Liu \& Wang, 2012; Yang \& He, 2013; Zhou, Tian, Zhao \& Zhao, 2015).

However, FA also has some shortcomings. The fixed-step factor and attractiveness do not seem to match the actual situation. Too many times of mutual attraction between fireflies lead to the oscillation phenomenon (Wang, Wang, Zhou, Sun, Zhao, Yu \& Cui, 2017), and is not conducive to the rapid convergence of the algorithm.

To overcome these shortcomings, some researchers first adjusted the parameters of FA. Yu et al. (Yu, Zhu, Ma \& Mao, 2015) proposed a variable step size of firefly algorithm (VSSFA), which explores the space with a larger step size in the early stage, and mines the optimal solution with a smaller step size in the later stage. Gandomi et al. (Gandomi, Yang, Talatahari \& Alavi, 2013) used 
12 chaotic maps to adjust $\alpha, \beta$ and $\gamma$. Experiments have found that the best chaos algorithm is an algorithm that uses Gauss map to adjust attractiveness parameters. Yelghi (Yelghi \& Köse, 2018) introduced tidal force into $\mathrm{FA}$, replacing the original attractiveness parameter $\beta$. Liu et al. (Liu, $\mathrm{Li}$, Deng \& Ren, 2020) proposed an attraction formula based on sigmoid, which reconstructed the definition of attraction $\beta$ and enhanced the local search ability of the algorithm. A novel courtship learning framework was proposed by Peng et al (Peng, Zhu, Deng \& Wu, 2020). It uses an archive mechanism to allow a female firefly to lead a weaker male firefly. This framework uses a logistic regression function to replace $\beta$ when solving the problem that the distance between two fireflies is too large and the attraction is close to 0 . This improvement well balances the exploration and exploitation of the algorithm.

Other scholars have improved the attraction model of FA. To reduce the computational time complexity, Wang (Wang, Wang, Sun \& Rahnamayan, 2016) proposed a random attraction model (RaFA). This algorithm allows the fireflies to randomly choose another firefly to move instead of moving to every other firefly. Subsequently, the author proposed a firefly algorithm with neighborhood attraction (NaFA) (Wang, et al., 2017). The algorithm selects $k$ neighbors around to move according to the subscript where the current firefly is located. Similarly, the algorithm greatly reduces computational time complexity. These "neighbors" proposed here are not neighbors in the real world, it is a neighbor selected based on the subscript of each firefly. The best neighbor guided strategy proposed by Wu et al. (Wu, Wu \& Peng, 2019) is also to reduce the oscillation during the movement of fireflies. The main idea is that each firefly is attracted by the best firefly among randomly selected neighbors. Zhao et al. (Zhao, Chen, Ye, Wang, Sun \& Lee, 2020) divided the firefly population into different levels according to fitness. Each firefly randomly selects two higher levels for learning. This model is called a level-based attraction model. Interestingly, a model called accurate partial attraction (PaFA) was proposed by Zhou et al (Zhou, Ding, Ma \& Tang, 2019). The difference between accurate partial attraction model and the neighborhood attraction model (NaFA) is that the former first sorts the entire population in ascending order of fitness, and then randomly selects $p$ fireflies from the brighter individuals to move. Pan (Pan, Xue \& Li, 2019) consider that a firefly will move to another firefly that is the brightest of the $n$ randomly selected neighbors. In the Yin-Yang firefly algorithm (Wang, Xu, Chau \& Xu, 2020), Wang improved the NaFA model. He sorted the entire population in descending order of fitness, starting from $i=2$, and randomly selecting an individual $j$ before $i$ to move.

In this paper, the attraction strategy based on euclidean metric (EM) is introduced into FA. This strategy allows fireflies to move according to their distance from other individuals. In order to balance the exploration and exploitation of the algorithm, the dimensional mutation strategy (DM) is added to the algorithm. Combining the above two strategies, we propose a firefly algorithm based on euclidean metric and dimensional mutation (EMDmFA). The difference with NaFA is that EMDmFA finds neighbors based on distance in the real world. To evaluate the performance of EMDmFA, experiments are conducted on 13 benchmark functions.

The rest of this paper is organized as follows. In Section 2, A brief review of the basic concepts of standard FA and its variants. Our approach EMDmFA is described in Section 3. Experimental results and analysis are presented in Section 4. Finally, the conclusion and future work are summarized in Section 5.

\section{RELATED WORK}

In this chapter, we will briefly introduce the concept, framework and variants of FA. FA is a metaheuristic swarm intelligence algorithm inspired by the flashing behavior of fireflies. It was developed by Yang in 2008. This algorithm follows the three idealized rules: (1) all fireflies are 
genderless. (2) the attractiveness is proportional to the brightness and distance. (3) the brightness of a firefly is determined by the landscape of the objective function.

In FA, the light intensity $I(r)$ is defined by (Yang, 2010).

$I(r)=I_{0} e^{-\gamma r^{2}}$

where $I_{0}$ is the light intensity at the light source. The attractiveness of a firefly is proportional to the intensity of light seen by its neighboring fireflies. It decreases monotonically with the increase of distance. The attractiveness is as follows.

$\beta(r)=\beta_{0} e^{-\gamma r^{m}},(m \geq 1)$,

where $\beta_{0}$ is the attractiveness at $r=0$, and Yang suggests that the value of $\mathrm{m}$ is equal to 2 .

For two fireflies $x_{i}$ and fireflies $x_{j}$, The distance between the two fireflies is calculated by Cartesian distance.

$r_{i j}=x_{i}-x_{j}=\sqrt{\sum_{d=1}^{D}\left(x_{i d}-x_{j d}\right)^{2}}$,

where $x_{i d}$ is the $d$ th component of the spatial coordinate of $x_{i}$.D is the dimension of the problem.

The movement of firefly $x_{i}$ to the brighter firefly $x_{j}$ is determined by:

$x_{i}(t+1)=x_{i}(t)+\beta_{0} e^{-\gamma r^{2}}\left(x_{j}(t)-x_{i}(t)\right)+\mathbf{a} \epsilon_{i}$,

where $\epsilon_{i}$ is a random value uniformly distributed in the range [-0.5,0.5], $t$ is the number of iterations and $\alpha$ is the step factor.

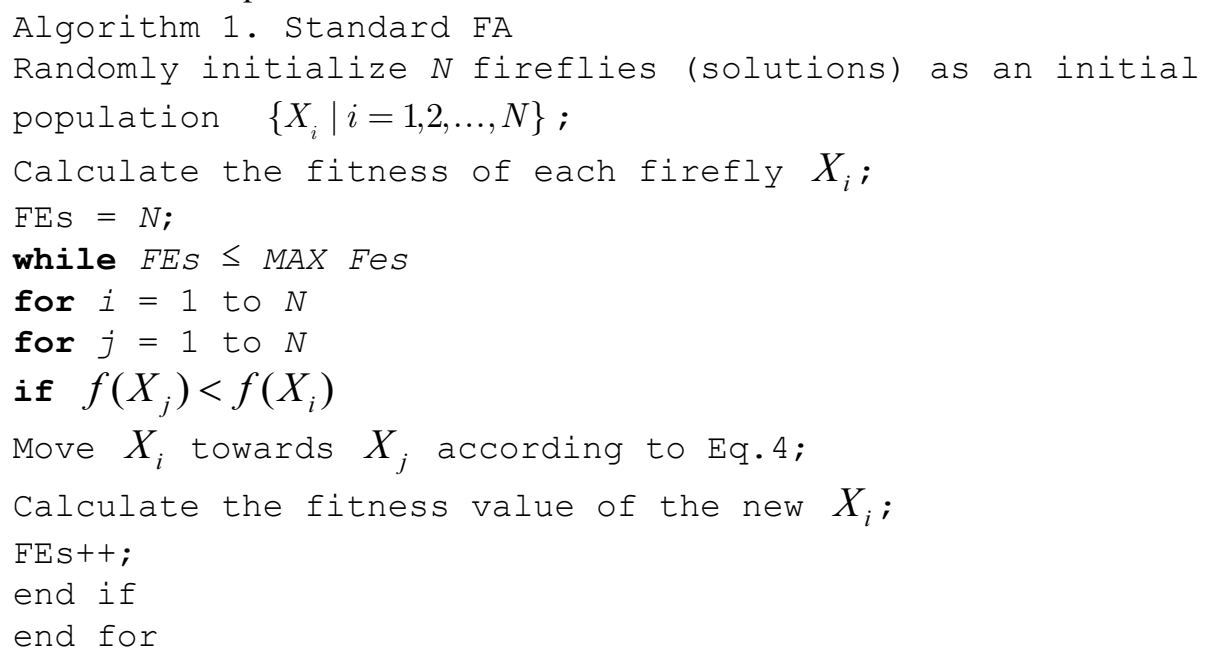


end for

end while

The Standard FA is described in Algorithm 1, where $\mathrm{N}$ is the population size, FEs is the number of fitness evaluations and MAX_FEs is the maximum number of fitness evaluations.

As a novel optimization algorithm, FA has been favored by many scholars in recent years, and many new variants of FA have been developed. Fister et al. (Fister Jr, Yang, Fister \& Brest, 2012) proposed a memetic-based firefly algorithm (MFA), in which $\alpha$ and $\beta$ are dynamically adjusted. The modification of MFA is as follows.

$\alpha(t+1)=\left(\frac{1}{9000}\right)^{\frac{1}{t}} \alpha(t)$,

$x_{i d}(t+1)=x_{i d}(t)+\beta\left(x_{j d}(t)-x_{i d}(t)\right)+\alpha(\mathrm{t}) s_{d} \epsilon_{i}$,

$\beta=\beta_{\min }+\left(\beta_{0}-\beta_{\min }\right) e^{-\gamma r^{2}}$,

$s_{d}=x_{d}^{\max }-x_{d}^{\min }$,

where $\beta_{\text {min }}$ is usually set to $0.2, s_{d}$ is the length of the domain of the initialization variable. $x_{d}^{\max }$ and $x_{d}^{\min }$ are the maximum and minimum boundaries of the variable, respectively.

In (Yu, et al., 2015), Yu proposed a variable step size firefly algorithm called VSSFA. He believes that a larger step size helps to explore a wider space, while a smaller step size is suitable for local mining and is conducive to algorithm convergence. Therefore, he proposed a step size update method. It is defined as follows:

$\alpha(t)=\frac{0.4}{1+e^{\left(0.015^{*}(t-\text { Max_-generation }) / 3\right)}}$,

where t represents the current iteration. Recent research shows that VSSFA does not seem to be suitable for high-dimensional problems (Wang, Cui, Sun, Rahnamayan \& Yang, 2017).

\section{PROPOSED FIREFLY ALGORITHM}

\subsection{Attraction Model Based on Euclidean Metric}

Inspired by the neighbor attraction model, this paper proposes a neighbor attraction model based on distance. In the real world of human society, "neighbor" is defined as a person whose home or residence is close to or near another person's home or residence. Therefore, we introduce the concept of neighbor based on distance into FA. 
Suppose there are 20 fireflies in the population, and the number of neighbors $k$ is set to 3 . Figure 1(a) shows the NaFA attraction model. Assuming that the current moving firefly is $x_{1}$, according to its movement rules, $x_{1}$ needs to be compared with the other six fireflies And judge whether to move. Since NaFA's neighbors are not neighbors in reality, $x_{1}$ may move to individuals close to it, or to those far away. Therefore, NaFA has a strong global search capability.

Figure 1(b) shows the proposed neighborhood attraction model based on distance. $x_{1}$ selects $k$ individuals closest to it to move. This makes EMDmFA have a strong local search ability, but may fall into a local optimum. In order to avoid this situation, we revised the comparison rules of fireflies. Assuming that $x_{1}$ is better than one of its neighbors $x_{7}, x_{1}$ is turned around and moved to a global best individual. This enhances the algorithm exploration capability and avoids falling into local optimum. EMDmFA these two ways of selecting moving objects well balance the exploration and exploitation of the algorithm. When the firefly $x_{i}$ moves to a brighter individual, Eq. (6) is used. When it moves to the global optimum, the following formula is used.

$x_{i d}(t+1)=x_{i d}(t)+\theta \beta\left(g_{b e s t}-x_{i d}(t)\right)+\alpha(\mathrm{t}) s_{d} \epsilon_{i}$,

Where $\theta$ is a random number in range $(0,1), g_{\text {best }}$ is the global best individual.

To put it simply, the EM strategy makes the firefly learn from the nearest neighbors. If the current firefly is better than a neighbor, let it learn from the best individual in the population.

\subsection{Dimensional Mutation Strategy}

Artificial bee colony(ABC) algorithm is an optimized algorithm developed based on bees with intelligent behavior (Karaboga \& Basturk, 2007). The strength of the $\mathrm{ABC}$ algorithm is its exploratory ability, so we decided to learn some experience from the advantages of the algorithm.

Brajević (Brajeviæ, Stanimiroviæ, Li \& Cao, 2020) proposed a new employed bee operator in his paper, described as follows.

$$
v_{i d}=x_{i m}+\varphi \cdot\left(x_{i m}-x_{k m}\right)
$$

where $v$ is a candidate food position, $m$ is a randomly selected index in the range $(1, D), D$ is dimension of the problem. $x_{k}$ represents an individual randomly selected from the population, $k \in\{1,2, \ldots, N\} . \varphi$ is a random number in range $(-1,1)$. It should be noted that the experimental solution $v$ is updated in all dimensions. The traditional $\mathrm{ABC}$ algorithm only updates one dimension in the hire bee stage, which limits its ability to explore space.

Inspired by this formula, we apply it to the global best individual of FA to enhance the algorithm's ability to escape the local optimal.

$$
g b e s t_{d}=g_{b e s t}+\varphi \cdot\left(\text { gbest }_{m}-x_{k m}\right)
$$




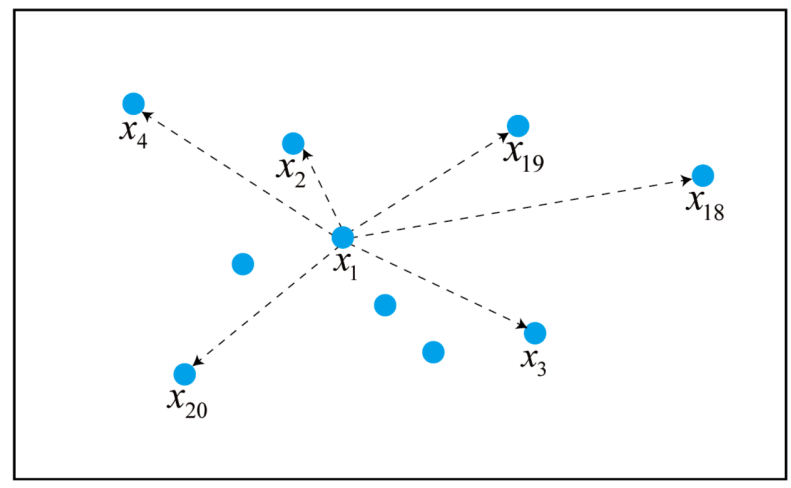

(a) Neighborhood attraction model

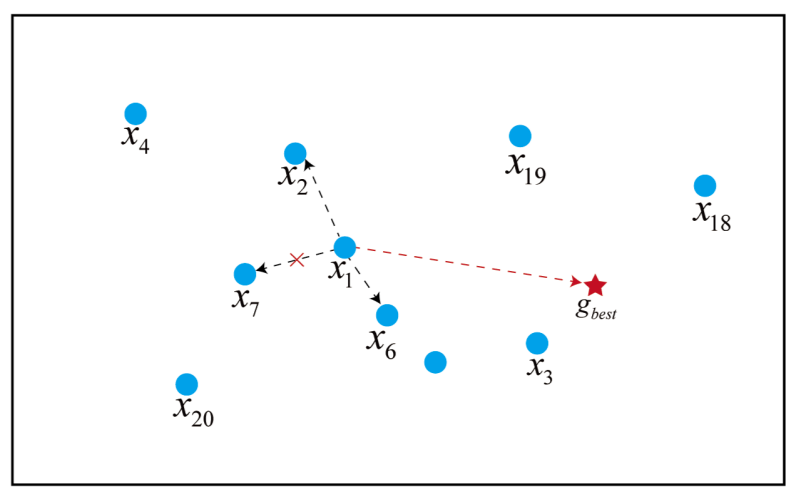

(b) Attraction model based on euclidean metric

\subsection{The Framework of EMDmFA}

The framework of the proposed EMDmFA is listed in algorithm 2, where $k$ is the number of neighbors of $x_{i}$ and $g_{\text {best }}$ is the global best individual with the best fitness value. To explain the framework of EMDmFA in detail, we have summarized four major steps.

1. Initialization: According to the formula $x_{i d}=l o w+(u p-l o w) \cdot \operatorname{rand}(0,1)$, randomly initialize $\mathrm{N}$ individuals and calculate their fitness values, where low and $u p$ are the lower and upper bounds for the dimension $\mathrm{d}$, respectively.

2. Update parameters: Update the parameter $\alpha$ according to Eq. 5.

3. Attraction and movement: Calculate the distance between $x_{i}$ and each firefly, and sort them in ascending order of distance. Select the top $k$ individuals after sorting to move (EM strategy). For example, suppose the population size is $N$, the firefly ready to move is $x_{i}$. the population sorted by distance is named SORT, and its size is $N-1$. then $x_{i}$ is compared with SORT[0], SORT[1], SORT[2] in turn. If its neighbor is brighter, then $x_{i}$ moves to its neighbor, otherwise, moves to the global best individual. Before the end of each iteration, use the DM strategy to update the global optimal individual (DM strategy). 
4. Stopping criteria: If the maximum number of evaluations is reached, the algorithm will be terminated, otherwise it will jump to the second step to continue execution.

\section{EXPERIMENTS STUDY}

To evaluate the performance of the proposed EMDmFA, we compared it with several latest FA variants on 13 classic benchmark functions and CEC2013 functions. We first use the classic test function to test the different values of the attention factors and the effectiveness of different strategies, and then use the CEC2013 test function to test the performance of the proposed algorithm. Thirteen benchmark functions include five unimodal functions, a step function, a noisy quadratic function and six multimodal functions. All functions are minimization problems, and their descriptions are shown in Table 1.

Compared with 13 classic test functions, 28 test functions of CEC2013 can better test the performance of the algorithm. A detailed description of CEC2013 can be found in (Liang, Qu, Suganthan \& Hernández-Díaz, 2013). CEC2013 test functions are divided into three groups, including 5 single-mode functions $f_{1}-f_{5}, 15$ multi-mode functions $f_{6}-f_{20}$ and 8 composite functions $f_{20}-f_{28}$.

\subsection{Experimental Setting}

To make a fair comparison on FA variants, the same parameter Settings were used in all experiments. Other algorithms all adopt the parameters provided in the literature (Wang, et al., 2017). The details of all the parameters of the involved algorithm set as shown in Table 2. EMDmFA uses the same parameter settings as MFA. In all experiments, the algorithm stop condition $M A X \quad F E S$ was set to $5.0 \mathrm{E}+5$, the dimension $\mathrm{D}$ of the problem is 30 . Each algorithm runs independently 30 times for each function.

\subsection{Effects of the Parameter K}

In NaFA, the author emphasized the importance of parameter $k$, and investigated the influence of different values of $k$ on the performance of the algorithm. EMDmFA moves through the distance between individual fireflies during the attraction process, and the number of neighbors has a greater impact on the capabilities of exploration and exploitation. When $k$ takes a small value, the firefly will explore a small space consisting of itself and its $k$ neighbors. When $k$ takes a larger value, the space for fireflies to explore is broader.

Table 3 lists the computational results obtained for different $k$ values of EMDmFA, where mean represents the average optimal fitness value. Same as NaFA, here assume $k$ is 2, 3, 4, 5, 7 and 9 respectively.

From the results in the table, it can be inferred that $k$ gets better results with smaller values. At the same time, it can be seen that as $k$ increases, the accuracy of the solutions of unimodal functions and some multimodal functions (except $f_{11}$ ) is gradually decreasing. This also shows that as the number of fireflies moves increases, it brings more uncertainty. When $k=2$, better solutions are obtained on $f_{1}, f_{2}, f_{6}, f_{12}$ and $f_{13}$, but the performance is worse on $f_{3}, f_{4}$ and $f_{11}$. The two cases of $k=3$ and $k=4$ have their own advantages. The former performs better on $f_{3}$ and obtains the optimal solution under different $k$ values. The latter performed well on $f_{4} \cdot f_{6}$ and $f_{11}$ are hardly affected by the $k$ value, indicating that the dimensional mutation strategy helps the algorithm jump out of the local optimum on these two functions. When $k=2,3,4$ and $5, f_{12}$ and $f_{13}$ can still obtain the same solution, which also shows the importance of this strategy. 
Table 1. Benchmark functions used in the experiments, where $D$ is the problem dimension

\begin{tabular}{|c|c|c|c|}
\hline Name & Function & Search Range & $\begin{array}{l}\text { Global } \\
\text { Optimum }\end{array}$ \\
\hline Sphere & $f_{1}(x)=\sum_{i=1}^{D} x^{2}$ & {$[-100,100]$} & 0 \\
\hline Schwefel 2.22 & $f_{2}(x)=\sum_{i=1}^{D}\left|x_{i}\right|+\prod_{i=1}^{D} x_{i}$ & {$[-10,10]$} & 0 \\
\hline Schwefel 1.2 & $f_{3}(x)=\sum_{i=1}^{D}\left(\sum_{j=1}^{i} x_{j}\right)^{2}$ & {$[-100,100]$} & 0 \\
\hline Schwefel 2.21 & $f_{4}(x)=\max \left\{\left|x_{i}\right|, 1 \leq i \leq D\right\}$ & {$[-100,100]$} & 0 \\
\hline Rosenbrock & $f_{5}(x)=\sum_{i=1}^{D}\left[100\left(x_{i+1}-x_{i}^{2}\right)^{2}+\left(1-x_{i}^{2}\right)^{2}\right]$ & {$[-30,30]$} & 0 \\
\hline Step & $f_{6}(x)=\sum_{i=1}^{D} x_{i}+0.5$ & {$[-100,100]$} & 0 \\
\hline Quartic with noise & $f_{7}(x)=\sum_{i=1}^{D} i x_{i}^{4}+$ random $[0,1)$ & {$[-1.28,1.28]$} & 0 \\
\hline Schwefel 2.26 & $f_{8}(x)=\sum_{i=1}^{D}-x_{i} \sin \left(\sqrt{\left|x_{i}\right|}\right)+418.9829 D$ & {$[-500,500]$} & 0 \\
\hline Rastrigin & $f_{9}(x)=\sum_{i=1}^{D}\left[x_{i}^{2}-10 \cos 2 \pi x_{i}+10\right]$ & {$[-5.12,5.12]$} & 0 \\
\hline Ackley & $f_{10}(x)=-20 \exp \left(-0.2 \sqrt{\frac{1}{D} \sum_{i=1}^{D} x_{i}^{2}}\right)-\exp \left(\frac{1}{D} \sum_{i=1}^{D} \cos \left(2 \pi x_{i}\right)\right)+20+e$ & {$[-32,32]$} & 0 \\
\hline Griewank & $f_{11}(x)=\frac{1}{4000} \sum_{i=1}^{D} x_{i}^{2}-\prod_{i=1}^{D} \cos \left(\frac{x_{i}}{\sqrt{i}}\right)+1$ & {$[-600,600]$} & 0 \\
\hline Penalized 1 & $\begin{array}{l}f_{i 2}(x)=\frac{\pi}{D}\left\{\sum_{i=1}^{D-1}\left(y_{i}-1\right)^{2}\left[1+\sin \left(\pi y_{i+1}\right)\right]+\left(y_{p}-1\right)^{2}+10 \sin ^{2}\left(\pi y_{1}\right)\right\}+ \\
\sum_{i=1}^{D} u\left(x_{i}, 10,100,4\right), y_{i}=1+\left(x_{i}+1\right) / 4 \\
u\left(x_{i}, a, k, m\right)=\left\{\begin{array}{l}u\left(x_{i}, a, k, m\right), x_{i}>a \\
0, \quad-a \leq x_{i} \leq a \\
k\left(-x_{i}-a\right)^{m}, x_{i}<-a\end{array}\right.\end{array}$ & {$[-50,50]$} & 0 \\
\hline Penalized 2 & 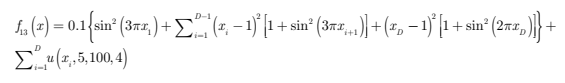 & {$[-50,50]$} & 0 \\
\hline
\end{tabular}

To determine the value of $k$, the Friedman Test was introduced (García, Fernández, Luengo \& Herrera, 2010). Table 4 lists the mean ranking of EMDmFA under different $k$ values. From the table, $k=4$ obtained the best ranking. The next experiment $k$ is set to 4 . 
Table 2. The parameters of the algorithms

\begin{tabular}{|l|l|l|l|l|l|}
\hline & $\alpha_{\text {min }}$ & $\alpha(0)$ & $\gamma$ & $\beta$ & $\beta_{\text {min }}$ \\
\hline FA (Yang, 2010) & - & 0.2 & 1.0 or $1 / \Gamma^{2}$ & $\beta_{0}=1.0$ & - \\
\hline $\begin{array}{l}\text { MFA (Fister Jr, et } \\
\text { al., 2012) }\end{array}$ & - & 0.5 & $1 / \Gamma^{2}$ & $\beta_{0}=1.0$ & 0.2 \\
\hline $\begin{array}{l}\text { RaFA (Wang, et } \\
\text { al., 2016) }\end{array}$ & - & 0.2 & 1.0 & $\beta_{0}=1.0$ & 0.2 \\
\hline $\begin{array}{l}\text { VSSFA (Yu, et al., } \\
\text { 2015) }\end{array}$ & - & - & 1.0 & $\beta_{0}=1.0$ & - \\
\hline $\begin{array}{l}\text { NaFA (Wang, et } \\
\text { al., 2017) }\end{array}$ & - & 0.5 & 1.0 & $\beta_{0}=1.0$ & 0.2 \\
\hline $\begin{array}{l}\text { WSSFA (Yu, Su, } \\
\text { Lu \& Huang, } \\
\text { 2014) }\end{array}$ & 0.2 & 0.5 & 1.0 & $\beta_{0}=1.0$ & 0.2 \\
\hline
\end{tabular}

\subsection{Effects of Different Strategy}

Through the experiment in section 4.2, we already know that when $k=4$, EMDmFA has excellent performance, also shows the effectiveness of the proposed strategy. The attraction model based on euclidean metric and dimensional mutation strategy can balance exploration and exploitation. In this chapter, we add two strategies to analyze the role of each strategy based on MFA. For the sake of simplicity, MFA combined with ED and DM is called EMDmFA. Because the ED strategy has a strong local search ability, it has a stronger ability to optimize the unimodal function, and the result is more accurate. This feature can be clearly seen from the $f_{1}-f_{4}$ functions in Table 5 .

But it is easy to fall into the local optimum on the multimodal function. The DM strategy has no obvious effect on the unimodal function, but it performs better than MFA on the multimodal function, which also shows that it has a strong ability to jump out of the local optimum. In the function $f_{11}-f_{13}$, the algorithm with the DM strategy obtains a more accurate solution than MFA. Combining these two strategies can balance the ablility of exploration and exploitation. It can be seen from Table 5 that EMDmFA is outstanding on 12 functions except $f_{3}$.

\subsection{Comparison of EMDmFA with other Lastst FA Variants}

In the previous chapter, $k$ set to 4 is considered the best choice. Table 6 lists the computational results when $k=4$. "Best" represents the optimal value obtained by the algorithm. "Mean" represents the average optimal value for 30 runs. "Worst" represents the worst value in 30 runs, and "Std Dev" is the standard deviation. As shown in Table 6, EMDmFA can still find the minimum value 0 on $f_{5}$ and $f_{9}$, indicating that the algorithm has a strong global search ability, but there is still the risk of falling into a local optimum and unable to escape. There is also a chance to find the approximate optimal solution on $f_{8}$. The algorithm can find the global optimal solution every time on $f_{6}, f_{11}$, $f_{12}$ and $f_{13}$.

Table 7 lists the comparison results of EMDmFA and FA, VSSFA, MFA, RaFA, NaFA. The necessary parameters are already declared in section 4.1. Please refer to Table 2 for the detailed parameter settings of each algorithm. The results of EMDmFA and the other five FA variants are 
International Journal of Cognitive Informatics and Natural Intelligence

Volume 15 • Issue 4

Table 3. Computational results of EMDmFA under different $k$ values

\begin{tabular}{|c|c|c|c|c|c|c|}
\hline Function & $\begin{array}{c}k=2 \\
\text { Mean }\end{array}$ & $\begin{array}{r}k=3 \\
\text { Mean }\end{array}$ & $\begin{array}{r}k=4 \\
\text { Mean }\end{array}$ & $\begin{array}{r}k=5 \\
\text { Mean }\end{array}$ & $\begin{array}{r}k=7 \\
\text { Mean }\end{array}$ & $\begin{array}{c}k=9 \\
\text { Mean }\end{array}$ \\
\hline$f_{1}$ & 4.59E-94 & $2.17 \mathrm{E}-62$ & $2.38 \mathrm{E}-46$ & $9.17 \mathrm{E}-37$ & $1.40 \mathrm{E}-25$ & $2.00 \mathrm{E}-19$ \\
\hline$f_{2}$ & $9.50 \mathrm{E}-48$ & $5.59 \mathrm{E}-32$ & $5.33 \mathrm{E}-24$ & $4.25 \mathrm{E}-19$ & $1.25 \mathrm{E}-13$ & $1.65 \mathrm{E}-10$ \\
\hline$f_{3}$ & $4.51 \mathrm{E}+00$ & $3.76 \mathrm{E}-60$ & $2.03 \mathrm{E}-44$ & $8.08 \mathrm{E}-35$ & $7.93 \mathrm{E}-24$ & $1.06 \mathrm{E}-17$ \\
\hline$f_{4}$ & $1.09 \mathrm{E}-04$ & $3.55 \mathrm{E}-13$ & $1.14 \mathrm{E}-23$ & $7.80 \mathrm{E}-19$ & $2.41 \mathrm{E}-13$ & $3.59 \mathrm{E}-10$ \\
\hline$f_{5}$ & $2.62 \mathrm{E}+01$ & $2.21 \mathrm{E}+01$ & $1.91 \mathrm{E}+01$ & $2.20 \mathrm{E}+01$ & $2.09 \mathrm{E}+01$ & $1.62 \mathrm{E}+01$ \\
\hline$f_{6}$ & $0.00 \mathrm{E}+00$ & $0.00 \mathrm{E}+00$ & $0.00 \mathrm{E}+00$ & $0.00 \mathrm{E}+00$ & $0.00 \mathrm{E}+00$ & $0.00 \mathrm{E}+00$ \\
\hline$f_{7}$ & $3.43 \mathrm{E}-04$ & 7.82E-04 & $8.88 \mathrm{E}-04$ & $1.17 \mathrm{E}-03$ & $1.08 \mathrm{E}-03$ & $1.62 \mathrm{E}-03$ \\
\hline$f_{8}$ & $5.94 \mathrm{E}+02$ & $7.13 \mathrm{E}+02$ & $5.95 \mathrm{E}+02$ & $3.48 \mathrm{E}+02$ & $6.01 \mathrm{E}+02$ & $3.86 \mathrm{E}+02$ \\
\hline$f_{9}$ & $3.49 \mathrm{E}-02$ & $4.15 \mathrm{E}-02$ & $5.87 \mathrm{E}-02$ & $8.28 \mathrm{E}-02$ & $1.38 \mathrm{E}-01$ & $1.25 \mathrm{E}+00$ \\
\hline$f_{10}$ & $3.88 \mathrm{E}-15$ & $3.88 \mathrm{E}-15$ & $3.88 \mathrm{E}-15$ & $3.76 \mathrm{E}-15$ & 8.05E-14 & $9.73 \mathrm{E}-11$ \\
\hline$f_{11}$ & $3.70 \mathrm{E}-18$ & $0.00 \mathrm{E}+00$ & $0.00 \mathrm{E}+00$ & $0.00 \mathrm{E}+00$ & $0.00 \mathrm{E}+00$ & $0.00 \mathrm{E}+00$ \\
\hline$f_{12}$ & $1.57 \mathrm{E}-32$ & $1.57 \mathrm{E}-32$ & $1.57 \mathrm{E}-32$ & $1.57 \mathrm{E}-32$ & $1.66 \mathrm{E}-27$ & $2.15 \mathrm{E}-21$ \\
\hline$f_{13}$ & $1.35 \mathrm{E}-32$ & $1.35 \mathrm{E}-32$ & $1.35 \mathrm{E}-32$ & $1.35 \mathrm{E}-32$ & $2.81 \mathrm{E}-26$ & $3.72 \mathrm{E}-20$ \\
\hline
\end{tabular}

Table 4. Mean rank achieved by the Friedman test for EMDmFA with different $k$ values

\begin{tabular}{|c|c|}
\hline EMDmFA & Mean rank \\
\hline$k=2$ & 3.27 \\
\hline$k=3$ & 2.96 \\
\hline$k=4$ & 2.73 \\
\hline$k=5$ & 3.04 \\
\hline$k=7$ & 4.27 \\
\hline$k=9$ & 4.73 \\
\hline
\end{tabular}


Table 5. Combination of MFA and different strategies

\begin{tabular}{|c|c|c|c|c|}
\hline Function & $\begin{array}{c}\text { MFA } \\
\text { Mean }\end{array}$ & $\begin{array}{c}\text { MFA + ED } \\
\text { Mean }\end{array}$ & $\begin{array}{c}\text { MFA + DM } \\
\text { Mean }\end{array}$ & $\begin{array}{c}\text { EMDmFA } \\
\text { Mean }\end{array}$ \\
\hline$f_{1}$ & $3.80 \mathrm{E}-06$ & $9.38 \mathrm{E}-46$ & $2.77 \mathrm{E}-07$ & $2.38 \mathrm{E}-46$ \\
\hline$f_{2}$ & $9.11 \mathrm{E}-04$ & $1.49 \mathrm{E}-23$ & 2.09E-04 & $5.33 \mathrm{E}-24$ \\
\hline$f_{3}$ & $1.33 \mathrm{E}-05$ & $5.51 \mathrm{E}-45$ & $1.48 \mathrm{E}-05$ & $2.03 \mathrm{E}-44$ \\
\hline$f_{4}$ & 8.84E-04 & $1.48 \mathrm{E}-23$ & $3.24 \mathrm{E}-04$ & $1.14 \mathrm{E}-23$ \\
\hline$f_{5}$ & $4.48 \mathrm{E}+01$ & $5.79 \mathrm{E}+01$ & $3.03 \mathrm{E}+01$ & $1.91 \mathrm{E}+01$ \\
\hline$f_{6}$ & 2.67E-01 & $0.00 \mathrm{E}+00$ & $0.00 \mathrm{E}+00$ & $0.00 \mathrm{E}+00$ \\
\hline$f_{7}$ & 5.79E-03 & $8.41 \mathrm{E}-03$ & $4.48 \mathrm{E}-03$ & $8.88 \mathrm{E}-04$ \\
\hline$f_{8}$ & $5.54 \mathrm{E}+03$ & $6.19 \mathrm{E}+03$ & $8.69 \mathrm{E}+02$ & $5.95 \mathrm{E}+02$ \\
\hline$f_{9}$ & $5.00 \mathrm{E}+01$ & $5.52 \mathrm{E}+01$ & $1.09 \mathrm{E}+01$ & $5.87 \mathrm{E}-02$ \\
\hline$f_{10}$ & 4.78E-04 & $5.18 \mathrm{E}-15$ & $1.21 \mathrm{E}-04$ & $3.88 \mathrm{E}-15$ \\
\hline$f_{11}$ & $1.04 \mathrm{E}-02$ & 4.02E-03 & $1.65 \mathrm{E}-04$ & $0.00 \mathrm{E}+00$ \\
\hline$f_{12}$ & $3.46 \mathrm{E}-03$ & $1.04 \mathrm{E}-02$ & $2.35 \mathrm{E}-09$ & $1.57 \mathrm{E}-32$ \\
\hline$f_{13}$ & 7.33E-04 & $1.46 \mathrm{E}-03$ & $5.72 \mathrm{E}-08$ & $1.35 \mathrm{E}-32$ \\
\hline
\end{tabular}

expressed in $w / t / l$, which means that compared with EMDmFA, EMDmFA wins in w functions, ties in $\mathrm{t}$ functions, and loses in 1 functions. It can be found in the results that VSSFA does not seem to be suitable for high-dimensional problems. MFA surpasses FA and VSSFA in most functions. It can be seen that fixed $\alpha$ and $\beta$ are not suitable for FA, and it is easy to fall into local optimum. For $f_{6}$ and $f_{11}$ function, RaFA, NaFA cannot always converge to the minimum value during the test. RaFA takes the lead in $f_{1}$, but it is far inferior to NaFA and EMDmFA in other functions. It is worth noting that EMDmFA is superior to NaFA in all functions. For unimodal functions $f_{1}-f_{5}$, the accuracy of EMDmFA solution is greatly improved. For the multimodal function $f_{8}-f_{13}$, our proposed algorithm has a stronger global search capability and the ability to find the global minimum. As described in Table 5, EMDmFA can obtain better solutions on $f_{5}, f_{8}$ and $f_{9}$.

To compare the performance of six FA variants, Friedman test is used (García, et al., 2010). Table 6 lists the mean ranking of all FA variants. According to the rank in the table, we can conclude that EMDmFA has achieved the best rank. Therefore, EMDmFA is better than the other five algorithms. 
Figure 2 and Figure 3 lists the partial convergence curves of all competing algorithms. In unimodal function, EMDmFA performs well and converges faster than NaFA, But on $f_{5}$, all six algorithms are easy to fall into local optimum. MFA, RaFA, NaFA and EMDmFA are easier to find the optimal solution on $f_{6}$. RaFA and EMDmFA converge faster than other algorithms on $f_{8}$ and have an approximate convergence rate. It's very obvious that EMDmFA outperforms the other five algorithms on $f_{8}$. It can be seen from the convergence curve of EMDmFA that in the iterative process, it falls into the local optimum for some time, and then jump out of the local optimum after a while. It also shows that the dimension variation strategy plays a key role. RaFA converges faster than EMDmFA on $f_{10}$ and $f_{13}$ in the early stage, but the later stage, RaFA cannot escape from the local optimum, and EMDmFA can still make the solution more accurate.

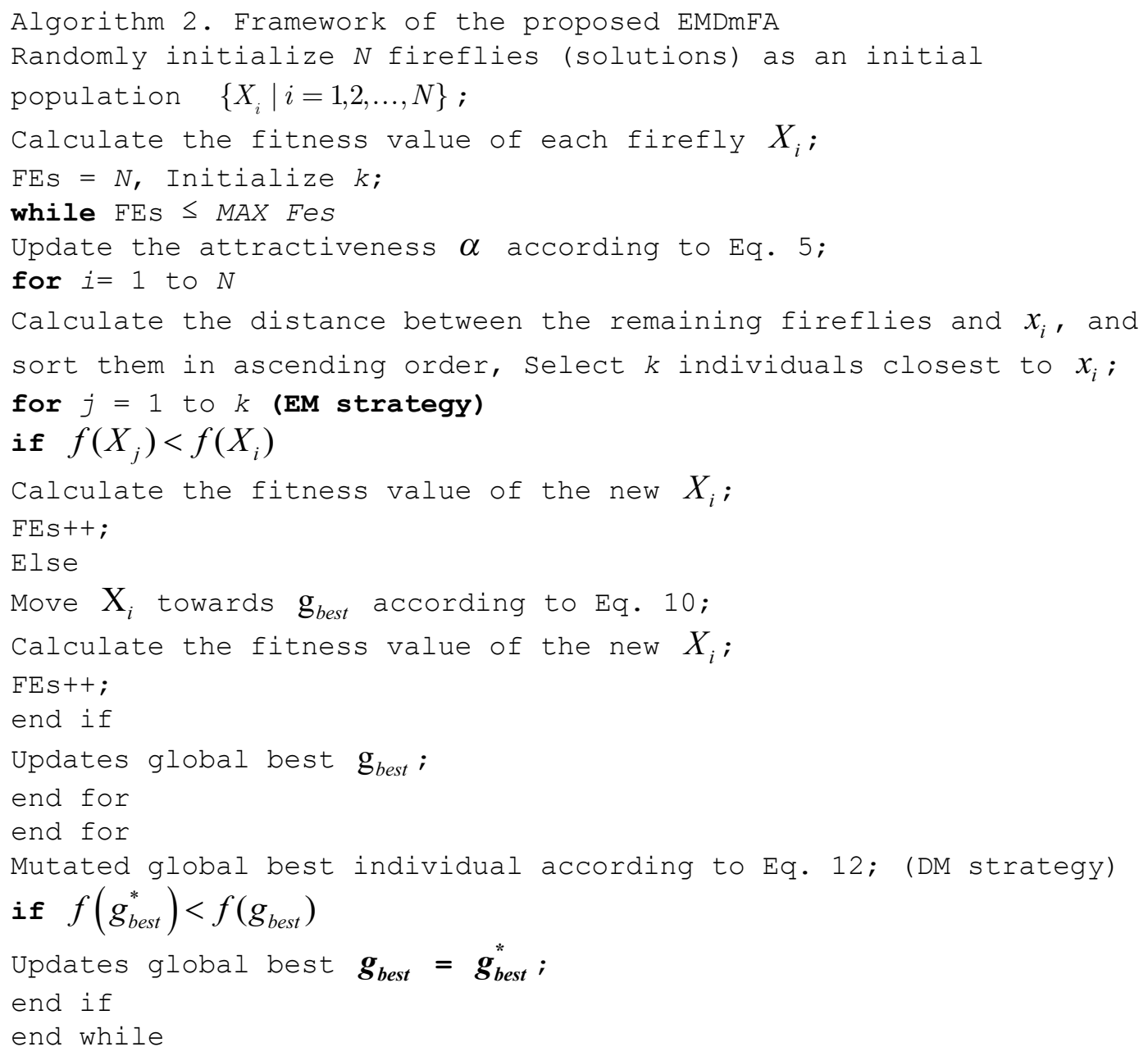

Table 7 summarizes the results of the Wilcoxon test of EMDmFA and other FA variants. According to the p-value, EMDmFA is significantly different from FA, VSSFA, MFA, RaFA and $\mathrm{NaFA}$, indicating that EMDmFA is better than these algorithms.

\subsection{Compare in CEC2013 Functions}

In this chapter, the CEC2013 test function is used to compare with other advanced FA variants, including standard FA, WSSFA, RaFA. The parameter settings of each algorithm are shown in Table 2. To be fair, the dimension D of the optimization problem is set to 30, and MAX_FEs is set 
to $5.0 \mathrm{E}+05$. Each algorithm is run 30 times and its average and standard deviation are taken. The results of the algorithm are in Table 8.

As can be seen in Table 8, EMDmFA achieved the best average value on 18 functions. In the

unimodal function $f_{1}-f_{5}$, EMDmFA only wins in 2 functions, the accuracy of $f_{1}$ and $f_{5}$ is more accurate than other algorithms. But in $f_{2}-f_{4}$, standard FA performs better than WSSFA, RaFA and EMDmFA. This may be related to the fixed $\alpha$ and the firefly distance being too far, resulting in $\beta$ close to 0 in the early stage of the algorithm. Therefore, FA is more like a random walk in the early stage, making it more exploratory. Comparing RaFA with EMDmFA, they have similar abilities in unimodal, multimodal and composite function, but in general, EMDmFA performs better.

In the multimodal function, standard FA is not good at mining solutions and escaping from local optima. Compared with EMDmFA, FA only wins once in function $f_{6}$, which is tied with WSSFA and EMDmFA on function $f_{8}$. RaFA and EMDmFA have similar results on these 15 multimodal functions, but the latter is still more accurate than the former in 9 functions. This shows that EMDmFA balances exploration and exploitation better than RaFA. In composite functions, EMDmFA outperforms other algorithms. In the comparison between EMDmFA and RaFA, the former has outstanding performance on 22 functions, and is tied with the latter on 6 functions. Overall, EMDmFA has better performance than the other three algorithms.

\section{CONCLUSION}

This paper proposes a neighborhood attraction firefly algorithm based on the Euclidean metric called EMDmFA. The algorithm employed two strategies to balance the ability between exploration and exploitation. First of all, the EM strategy reduces the computational time complexity and has strong local search capabilities. When a firefly moves to its neighbors, it will choose the k nearest neighbors as the learning target. Second, the DM strategy helps the optimal individual escape from the local optimal. We verified the different tendencies of the proposed two strategies between exploration and exploitation capabilities. The results on 13 classic and CEC 2013 test functions show that EMDmFA is more competitive than other FA variants.

The key parameter $k$ of EMDmFA has a significant influence on algorithm performance. According to experiments, we conclude that $k=4$ is a more appropriate choice. But $k$ should take different values at different stages of the algorithm. So our future work direction is to adopt a dynamic method to adjust $k$.

\section{ACKNOWLEDGMENT}

This work was supported by the National Natural Science Foundation of China [grant number 61866014, 61862027 and 61962024]; the National Natural Science Foundation of Jiangxi Province [grant number 20192BAB207032]; and the 15th Student Research Project of Jiangxi University of Finance and Economics [grant number 20200612092225812]. 
International Journal of Cognitive Informatics and Natural Intelligence Volume $15 \cdot$ Issue 4

Figure 2. The convergence curves of FA, VSSFA, MFA, RaFA, NaFA, EMDmFA

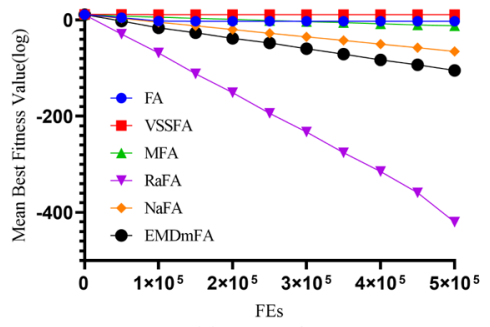

(a) Sphere

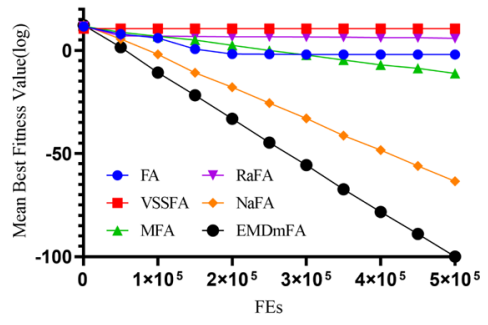

(c) Schwefel 1.2

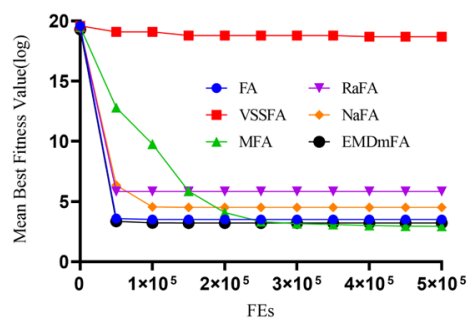

(e) Rosenbrock

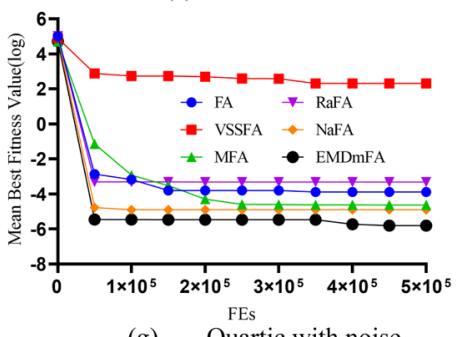

(g) Quartic with noise

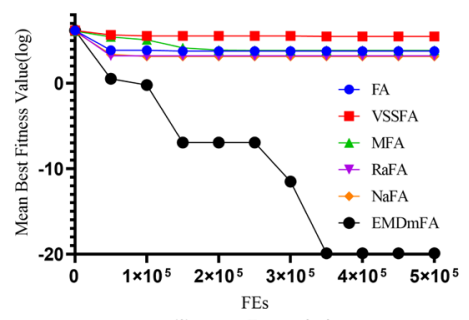

(i) Rastrigin

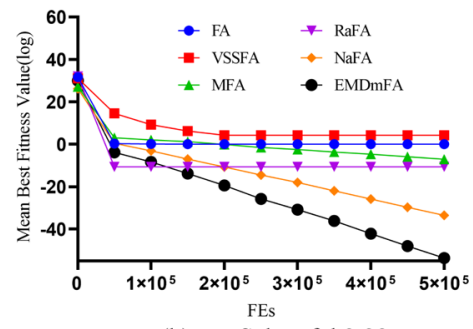

(b) Schwefel 2.22

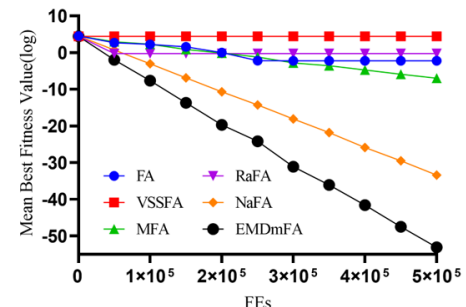

(d) Schwefel 2.21

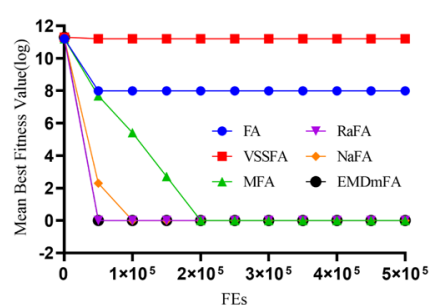

(f) Step

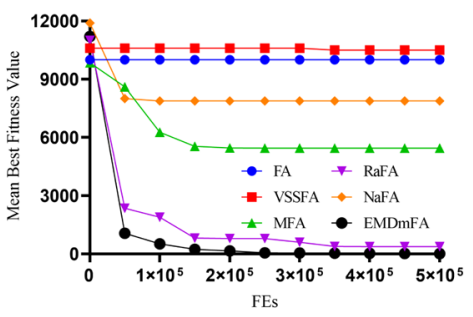

(h) Schwefel 2.26

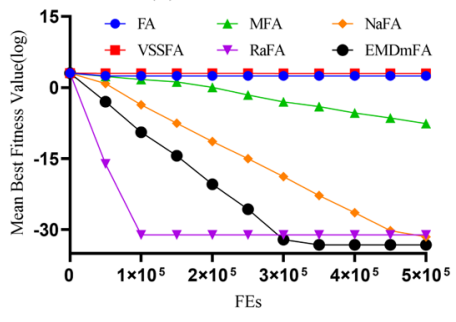

(j) Ackley 
Figure 3. The convergence curves of FA, VSSFA, MFA, RaFA, NaFA, EMDmFA - Continued

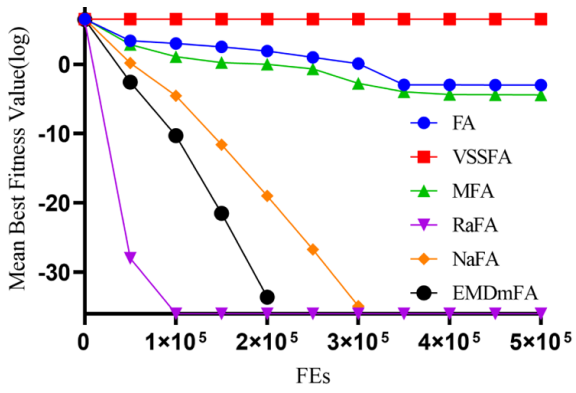

(k) Griewank

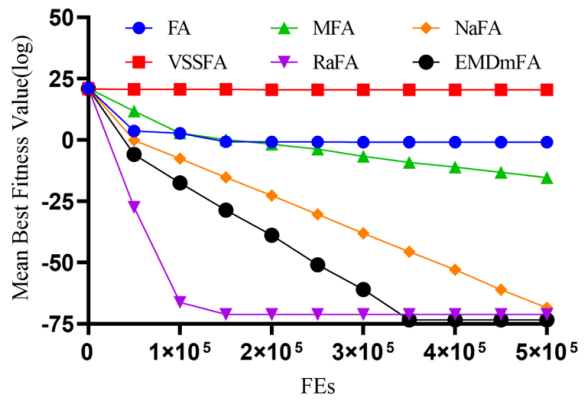

(1) Penalized 2

Table 6. Mean rank achieved by the Friedman test for the six FA variants

\begin{tabular}{|c|c|}
\hline Algorithm & Mean rank \\
\hline FA & 4.66 \\
\hline VSSFA & 6.00 \\
\hline MFA & 3.46 \\
\hline RaFA & 3.31 \\
\hline NaFA & 2.62 \\
\hline EMDmFA & 1.15 \\
\hline
\end{tabular}

Table 7. Wilcoxon test between EMDmFA and the other FA variants on the benchmark functions

\begin{tabular}{|c|c|c|c|}
\hline Comparison & R+ & R- & $\boldsymbol{p}$-value \\
\hline EMDmFA vs. FA & 91 & 0 & 0.001 \\
\hline EMDmFA vs. VSSFA & 91 & 0 & 0.001 \\
\hline EMDmFA vs. MFA & 91 & 0 & 0.002 \\
\hline EMDmFA vs. RaFA & 78 & 13 & 0.023 \\
\hline EMDmFA vs. NaFA & 91 & 0 & 0.001 \\
\hline
\end{tabular}


Table 8. Experimental comparison results of 4 algorithms on CEC2013 test functions

\begin{tabular}{|c|c|c|c|c|c|}
\hline Function & & $\mathbf{F A}$ & WSSFA & RaFA & EMDmFA \\
\hline$f_{1}$ & $\begin{array}{l}\text { Mean } \\
\text { SD }\end{array}$ & $\begin{array}{c}4.92 \mathrm{E}-02 \\
3.88 \mathrm{E}-03\end{array}$ & $3.56 \mathrm{E}+042.93 \mathrm{E}+03$ & $\begin{array}{l}8.56 \mathrm{E}-13 \\
2.80 \mathrm{E}-13\end{array}$ & $\begin{array}{c}2.50 \mathrm{E}-13 \\
6.94 \mathrm{E}-14\end{array}$ \\
\hline$f_{2}$ & $\begin{array}{l}\text { Mean } \\
\text { SD }\end{array}$ & $6.07 \mathrm{E}+041.91 \mathrm{E}+04$ & $3.76 \mathrm{E}+085.55 \mathrm{E}+07$ & $1.84 \mathrm{E}+075.02 \mathrm{E}+06$ & $\begin{array}{r}1.50 \mathrm{E}+06 \\
7.64 \mathrm{E}+05\end{array}$ \\
\hline$f_{3}$ & $\begin{array}{l}\text { Mean } \\
\text { SD }\end{array}$ & $\begin{array}{c}3.28 \mathrm{E}+07 \\
3.81 \mathrm{E}+07\end{array}$ & $1.61 \mathrm{E}+131.69 \mathrm{E}+13$ & $2.44 \mathrm{E}+091.60 \mathrm{E}+09$ & $\begin{array}{l}5.04 \mathrm{E}+07 \\
9.90 \mathrm{E}+07\end{array}$ \\
\hline & $\begin{array}{l}\text { Mean } \\
\text { SD }\end{array}$ & $8.64 \mathrm{E}+025.31 \mathrm{E}+02$ & $6.31 \mathrm{E}+04$ 7.27E+03 & $1.63 \mathrm{E}+044.84 \mathrm{E}+03$ & $\begin{array}{c}1.65 \mathrm{E}+03 \\
1.21 \mathrm{E}+03\end{array}$ \\
\hline$f_{5}$ & $\begin{array}{l}\text { Mean } \\
\text { SD }\end{array}$ & $\begin{array}{c}8.22 \mathrm{E}-02 \\
1.09 \mathrm{E}-02\end{array}$ & $7.11 \mathrm{E}+031.19 \mathrm{E}+03$ & $2.29 \mathrm{E}+014.25 \mathrm{E}+00$ & $\begin{array}{c}1.43 \mathrm{E}-03 \\
1.59 \mathrm{E}-04\end{array}$ \\
\hline$f_{6}$ & $\begin{array}{l}\text { Mean } \\
\text { SD }\end{array}$ & $1.24 \mathrm{E}+011.95 \mathrm{E}+01$ & $4.74 \mathrm{E}+036.58 \mathrm{E}+02$ & $7.98 \mathrm{E}+012.71 \mathrm{E}+01$ & $\begin{array}{c}3.99 \mathrm{E}+01 \\
2.58 \mathrm{E}+01\end{array}$ \\
\hline$f_{7}$ & $\begin{array}{l}\text { Mean } \\
\text { SD }\end{array}$ & $9.18 \mathrm{E}+061.37 \mathrm{E}+07$ & $2.47 \mathrm{E}+032.12 \mathrm{E}+03$ & $8.40 \mathrm{E}+011.51 \mathrm{E}+01$ & $\begin{array}{c}4.38 \mathrm{E}+01 \\
1.77 \mathrm{E}+01\end{array}$ \\
\hline$f_{8}$ & $\begin{array}{l}\text { Mean } \\
\text { SD }\end{array}$ & $\begin{array}{l}2.09 \mathrm{E}+01 \\
4.67 \mathrm{E}-02\end{array}$ & $\begin{array}{l}2.09 \mathrm{E}+01 \\
4.03 \mathrm{E}-02\end{array}$ & $\begin{array}{l}2.10 \mathrm{E}+01 \\
5.89 \mathrm{E}-02\end{array}$ & $\begin{array}{l}2.09 \mathrm{E}+01 \\
1.05 \mathrm{E}-01\end{array}$ \\
\hline$J$ & $\begin{array}{l}\text { Mean } \\
\text { SD }\end{array}$ & $4.42 \mathrm{E}+013.20 \mathrm{E}+00$ & $\begin{array}{l}3.92 \mathrm{E}+01 \\
9.71 \mathrm{E}-01\end{array}$ & $2.20 \mathrm{E}+013.68 \mathrm{E}+00$ & $\begin{array}{c}1.52 \mathrm{E}+01 \\
3.25 \mathrm{E}+00\end{array}$ \\
\hline$f_{10}$ & $\begin{array}{l}\text { Mean } \\
\text { SD }\end{array}$ & $\begin{array}{c}6.10 \mathrm{E}-01 \\
5.80 \mathrm{E}-02\end{array}$ & $4.68 \mathrm{E}+035.32 \mathrm{E}+02$ & $2.85 \mathrm{E}+017.75 \mathrm{E}+00$ & $\begin{array}{l}3.03 \mathrm{E}-02 \\
2.34 \mathrm{E}-02\end{array}$ \\
\hline$f_{11}$ & $\begin{array}{l}\text { Mean } \\
\text { SD }\end{array}$ & $7.35 \mathrm{E}+021.50 \mathrm{E}+02$ & $6.30 \mathrm{E}+024.05 \mathrm{E}+01$ & $7.18 \mathrm{E}+011.72 \mathrm{E}+01$ & $\begin{array}{c}8.55 \mathrm{E}+01 \\
2.52 \mathrm{E}+01\end{array}$ \\
\hline$f_{12}$ & $\begin{array}{l}\text { Mean } \\
\text { SD }\end{array}$ & $7.32 \mathrm{E}+02 \quad 1.32 \mathrm{E}+02$ & $6.37 \mathrm{E}+024.41 \mathrm{E}+01$ & $6.67 \mathrm{E}+011.95 \mathrm{E}+01$ & $\begin{array}{c}7.99 \mathrm{E}+01 \\
2.28 \mathrm{E}+01\end{array}$ \\
\hline$f_{13}$ & $\begin{array}{l}\text { Mean } \\
\text { SD }\end{array}$ & $8.47 \mathrm{E}+021.40 \mathrm{E}+02$ & $6.44 \mathrm{E}+024.27 \mathrm{E}+01$ & $1.58 \mathrm{E}+022.85 \mathrm{E}+01$ & $\begin{array}{c}1.71 \mathrm{E}+02 \\
4.70 \mathrm{E}+01\end{array}$ \\
\hline$f_{14}$ & $\begin{array}{l}\text { Mean } \\
\text { SD }\end{array}$ & $4.76 \mathrm{E}+037.65 \mathrm{E}+02$ & $7.22 \mathrm{E}+033.48 \mathrm{E}+02$ & $3.67 \mathrm{E}+037.03 \mathrm{E}+02$ & $\begin{array}{c}3.40 \mathrm{E}+03 \\
6.25 \mathrm{E}+02\end{array}$ \\
\hline$f_{15}$ & $\begin{array}{l}\text { Mean } \\
\text { SD }\end{array}$ & $4.58 \mathrm{E}+036.62 \mathrm{E}+02$ & $7.31 \mathrm{E}+032.86 \mathrm{E}+02$ & $3.31 \mathrm{E}+037.50 \mathrm{E}+02$ & $\begin{array}{c}3.38 \mathrm{E}+03 \\
6.62 \mathrm{E}+02\end{array}$ \\
\hline$f_{16}$ & $\begin{array}{l}\text { Mean } \\
\text { SD }\end{array}$ & $\begin{array}{c}4.07 \mathrm{E}-01 \\
1.41 \mathrm{E}-01\end{array}$ & $\begin{array}{l}2.34 \mathrm{E}+00 \\
2.56 \mathrm{E}-01\end{array}$ & $\begin{array}{c}3.20 \mathrm{E}-01 \\
2.54 \mathrm{E}-01\end{array}$ & $\begin{array}{c}1.82 \mathrm{E}-01 \\
1.08 \mathrm{E}-01\end{array}$ \\
\hline$f_{17}$ & $\begin{array}{l}\text { Mean } \\
\text { SD }\end{array}$ & $9.21 \mathrm{E}+021.50 \mathrm{E}+02$ & $1.08 \mathrm{E}+037.28 \mathrm{E}+01$ & $6.86 \mathrm{E}+019.19 \mathrm{E}+00$ & $\begin{array}{c}1.31 \mathrm{E}+02 \\
3.09 \mathrm{E}+01\end{array}$ \\
\hline$f_{18}$ & $\begin{array}{l}\text { Mean } \\
\text { SD }\end{array}$ & $8.50 \mathrm{E}+022.05 \mathrm{E}+02$ & $1.08 \mathrm{E}+038.65 \mathrm{E}+01$ & $7.08 \mathrm{E}+011.41 \mathrm{E}+01$ & $\begin{array}{c}1.31 \mathrm{E}+02 \\
2.70 \mathrm{E}+01\end{array}$ \\
\hline$f_{19}$ & $\begin{array}{l}\text { Mean } \\
\text { SD }\end{array}$ & $1.18 \mathrm{E}+021.22 \mathrm{E}+01$ & $2.21 \mathrm{E}+056.82 \mathrm{E}+04$ & 7.96E+00 3.57E+00 & $\begin{array}{c}4.94 \mathrm{E}+00 \\
1.76 \mathrm{E}+00\end{array}$ \\
\hline$f_{20}$ & $\begin{array}{l}\text { Mean } \\
\text { SD }\end{array}$ & $\begin{array}{l}1.50 \mathrm{E}+01 \\
8.97 \mathrm{E}-02\end{array}$ & $\begin{array}{l}1.50 \mathrm{E}+01 \\
3.55 \mathrm{E}-04\end{array}$ & $\begin{array}{l}1.49 \mathrm{E}+01 \\
4.36 \mathrm{E}-01\end{array}$ & $\begin{array}{c}1.23 \mathrm{E}+01 \\
1.41 \mathrm{E}+00\end{array}$ \\
\hline$f_{21}$ & $\begin{array}{l}\text { Mean } \\
\text { SD }\end{array}$ & $3.26 \mathrm{E}+029.65 \mathrm{E}+01$ & $2.86 \mathrm{E}+03 \quad 1.16 \mathrm{E}+02$ & $4.06 \mathrm{E}+026.22 \mathrm{E}+01$ & $\begin{array}{c}3.18 \mathrm{E}+02 \\
8.61 \mathrm{E}+01\end{array}$ \\
\hline$f_{22}$ & $\begin{array}{l}\text { Mean } \\
\text { SD }\end{array}$ & $6.75 \mathrm{E}+03$ 8.81E+02 & $8.02 \mathrm{E}+032.13 \mathrm{E}+02$ & $4.32 \mathrm{E}+03 \quad 1.07 \mathrm{E}+03$ & $\begin{array}{l}4.10 \mathrm{E}+03 \\
9.46 \mathrm{E}+02\end{array}$ \\
\hline$f_{23}$ & $\begin{array}{l}\text { Mean } \\
\text { SD }\end{array}$ & $6.69 \mathrm{E}+037.20 \mathrm{E}+02$ & $8.02 \mathrm{E}+032.58 \mathrm{E}+02$ & $4.71 \mathrm{E}+038.41 \mathrm{E}+02$ & $\begin{array}{c}3.82 \mathrm{E}+03 \\
6.76 \mathrm{E}+02\end{array}$ \\
\hline
\end{tabular}


Table 8.Continued

\begin{tabular}{|c|c|c|c|c|c|}
\hline Function & & FA & WSSFA & RaFA \\
\hline$f_{24}$ & $\begin{array}{c}\text { Mean } \\
\text { SD }\end{array}$ & $\begin{array}{c}5.14 \mathrm{E}+02 \\
8.88 \mathrm{E}+01\end{array}$ & $3.64 \mathrm{E}+028.05 \mathrm{E}+00$ & $2.46 \mathrm{E}+021.01 \mathrm{E}+01$ & $\begin{array}{c}2.33 \mathrm{E}+02 \\
1.31 \mathrm{E}+01\end{array}$ \\
\hline$f_{25}$ & Mean & $\begin{array}{c}4.28 \mathrm{E}+02 \\
2.40 \mathrm{E}+01\end{array}$ & $3.89 \mathrm{E}+026.68 \mathrm{E}+00$ & $2.88 \mathrm{E}+021.62 \mathrm{E}+01$ \\
$2.52 \mathrm{E}+01$
\end{tabular}

Table 9. Rank mean test results of 3 algorithms on the CEC2013 test functions

\begin{tabular}{|c|c|}
\hline Algorithm & Mean rank \\
\hline FA & 2.95 \\
\hline WSSFA & 3.52 \\
\hline RaFA & 2.14 \\
\hline EMDmFA & 1.39 \\
\hline
\end{tabular}

Table 10. Wilcoxon test between EMDmFA and the other FA variants on the CEC2013 test functions

\begin{tabular}{|c|c|c|c|}
\hline Comparison & R+ & R- & $\boldsymbol{p}$-value \\
\hline EMDmFA vs. FA & 302.00 & 76.00 & 0.007 \\
\hline EMDmFA vs. WSSFA & 378.00 & 14.00 & 0.000 \\
\hline EMDmFA vs. RaFA & 322.50 & 14.66 & 0.007 \\
\hline
\end{tabular}




\section{REFERENCES}

Brajeviæ, I., Stanimiroviæ, P. S., Li, S., \& Cao, X. (2020). A Hybrid Firefly and Multi-Strategy Artificial Bee Colony Algorithm. International Journal of Computational Intelligence Systems, 13(1), 810-821. doi:10.2991/ ijcis.d.200612.001

Fister, I., Jr., Yang, X.-S., Fister, I., \& Brest, J. (2012). Memetic firefly algorithm for combinatorial optimization. arXiv preprint arXiv: 1204.5165 .

Gandomi, A. H., Yang, X.-S., Talatahari, S., \& Alavi, A. H. (2013). Firefly algorithm with chaos. Communications in Nonlinear Science and Numerical Simulation, 18(1), 89-98. doi:10.1016/j.cnsns.2012.06.009

García, S., Fernández, A., Luengo, J., \& Herrera, F. (2010). Advanced nonparametric tests for multiple comparisons in the design of experiments in computational intelligence and data mining: Experimental analysis of power. Information Sciences, 180(10), 2044-2064. doi:10.1016/j.ins.2009.12.010

Karaboga, D., \& Basturk, B. (2007). A powerful and efficient algorithm for numerical function optimization: Artificial bee colony (ABC) algorithm. Journal of Global Optimization, 39(3), 459-471. doi:10.1007/s10898007-9149-x

Kennedy, J., \& Eberhart, R. (1995). Particle swarm optimization. Proceedings of ICNN'95-International Conference on Neural Networks, 1942-1948. doi:10.1109/ICNN.1995.488968

Liang, J., Qu, B., Suganthan, P., \& Hernández-Díaz, A. G. (2013). Problem definitions and evaluation criteria for the CEC 2013 special session on real-parameter optimization. Computational Intelligence Laboratory, Zhengzhou University, Zhengzhou, China and Nanyang Technological University, Singapore. Technical Report, 201212(34), 281-295.

Liu, A., Li, P., Deng, X., \& Ren, L. (2020). A sigmoid attractiveness based improved firefly algorithm and its applications in IIR filter design. Connection Science, 33(1), 1-25. doi:10.1080/09540091.2020.1742660

Pan, X., Xue, L., \& Li, R. (2019). A new and efficient firefly algorithm for numerical optimization problems. Neural Computing \& Applications, 31(5), 1445-1453. doi:10.1007/s00521-018-3449-6

Peng, H., Zhu, W., Deng, C., \& Wu, Z. (2020). Enhancing firefly algorithm with courtship learning. Information Sciences, 543, 18-42. doi:10.1016/j.ins.2020.05.111

Wang, G., Guo, L., Duan, H., Liu, L., \& Wang, H. (2012). A modified firefly algorithm for UCAV path planning. International Journal of Hybrid Information Technology, 5(3), 123-144.

Wang, H., Cui, Z., Sun, H., Rahnamayan, S., \& Yang, X.-S. (2017). Randomly attracted firefly algorithm with neighborhood search and dynamic parameter adjustment mechanism. Soft Computing, 21(18), 5325-5339. doi:10.1007/s00500-016-2116-z

Wang, H., Wang, W., Sun, H., \& Rahnamayan, S. (2016). Firefly algorithm with random attraction. International Journal of Bio-inspired Computation, 8(1), 33-41. doi:10.1504/IJBIC.2016.074630

Wang, H., Wang, W., Zhou, X., Sun, H., Zhao, J., Yu, X., \& Cui, Z. (2017). Firefly algorithm with neighborhood attraction. Information Sciences, 382, 374-387. doi:10.1016/j.ins.2016.12.024

Wang, W., Xu, L., Chau, K., \& Xu, D. (2020). Yin-Yang firefly algorithm based on dimensionally Cauchy mutation. Expert Systems with Applications, 150, 113216. doi:10.1016/j.eswa.2020.113216

Wu, S., Wu, Z., \& Peng, H. (2019). Enhancing Firefly Algorithm with Best Neighbor Guided Search Strategy. Wuhan University Journal of Natural Sciences, 24(6), 524-536. doi:10.1007/s11859-019-1432-4

Yang, X.-S. (2010). Nature-inspired metaheuristic algorithms. Luniver Press.

Yang, X.-S., \& Deb, S. (2009). Cuckoo search via Lévy flights. 2009 World congress on nature \& biologically inspired computing (NaBIC), 210-214. doi:10.1109/NABIC.2009.5393690

Yang, X.-S., \& He, X. (2013). Firefly algorithm: recent advances and applications. International Journal of Swarm Intelligence, 1(1), 36-50. 
Yelghi, A., \& Köse, C. (2018). A modified firefly algorithm for global minimum optimization. Applied Soft Computing, 62, 29-44. doi:10.1016/j.asoc.2017.10.032

Yu, S., Su, S., Lu, Q., \& Huang, L. (2014). A novel wise step strategy for firefly algorithm. International Journal of Computer Mathematics, 91(12), 2507-2513. doi:10.1080/00207160.2014.907405

Yu, S., Zhu, S., Ma, Y., \& Mao, D. (2015). A variable step size firefly algorithm for numerical optimization. Applied Mathematics and Computation, 263, 214-220. doi:10.1016/j.amc.2015.04.065

Zhao, J., Chen, W., Ye, J., Wang, H., Sun, H., \& Lee, I. (2020). Firefly Algorithm Based on Level-Based Attracting and Variable Step Size. IEEE Access : Practical Innovations, Open Solutions, 8, 58700-58716. doi:10.1109/ ACCESS.2020.2981656

Zhou, C., Tian, L., Zhao, H., \& Zhao, K. (2015). A method of two-dimensional Otsu image threshold segmentation based on improved firefly algorithm. In 2015 IEEE international conference on cyber technology in automation, control, and intelligent systems (CYBER). IEEE.

Zhou, L., Ding, L., Ma, M., \& Tang, W. (2019). An accurate partially attracted firefly algorithm. Computing, 101(5), 477-493. doi:10.1007/s00607-018-0645-2 